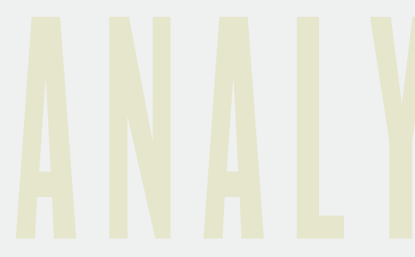

\section{Student Author}

Katelyn Reavis is a 2014 graduate of the Purdue University College of Liberal Arts. Reavis majored in anthropology and has participated in the Margo Katherine Wilke Undergraduate Research Internship program since 2012. Her research interests include bioarchaeology, gerontology, health, Andean archaeology, and paleodemography.

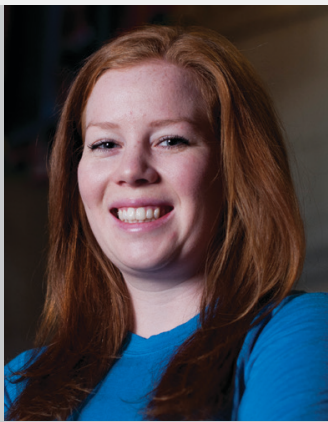
As a student, she served as the president of the Purdue Anthropology SocieTy (PAST), interned at Poudre Valley Hospital in Fort Collins, Colorado, and attended the PIARA bioarchaeology field school in Ancash, Peru. She is an assistant softball coach at McCutcheon High School and an athletic tutor at Purdue University.

\section{Mentor}

Michele R. Buzon has degrees in anthropology from Loyola University Chicago (BS) and the University of California, Santa Barbara (MA and $\mathrm{PhD}$ ). She is currently an associate professor of anthropology at Purdue University. With support from the National Geographic Society and the National Science Foundation, she has been investigating ancient

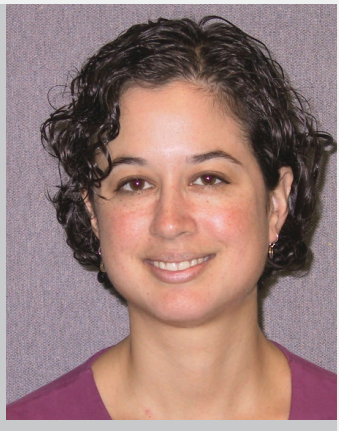
identity and health in people buried at archaeological sites in the Nile Valley of Africa. Specifically, Buzon's work has researched the consequences of EgyptianNubian interaction on the lives of individuals who lived during the New Kingdom and Napatan periods at the site of Tombos in northern Sudan.

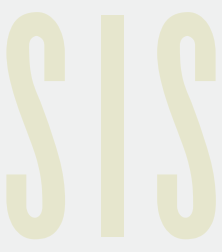

\section{Abstract}

The understanding of older adult life experiences is deficient when compared to younger adults and children in the archaeological record. Research has been devoted toward aging techniques and studies of osteoarthritis, but there are few discussions describing senescence, the cumulative process of aging, in the past. Most research includes the oldest cohort (45 years and above) within the broad category of adults, but it is useful to look at this demographic separately. Skeletal remains were analyzed from the site of Tombos (ancient Nubia) dated to the New Kingdom and the Napatan Periods ( 1400-650 BC). The focus of the analysis was on the pathological conditions and how this cohort's life experiences contribute to what is known about senescence today. It was hypothesized that individuals who reached extreme old age $(45+)$ would exhibit low signs of pathological and nutritional stress due to their abilities to escape chronic disease and disability. Results show there was a mix of disease survivors and disease escapers from the sample. Most individuals were in their 70s (39.1\%), but age distributions were relatively equal among the 40s, 50s, 60s, and 80s. Many individuals were robust and displayed low frequencies of nutritional or infectious lesions (less than 14\%). All individuals had some form of arthritis, but there was a wide range in severity. Two case studies are presented to detail disease survivors.

Reavis, K. (2014). Skeletal analysis: Investigating senescence in ancient Nubia. Journal of Purdue Undergraduate Research, 4, 40-47. http://dx.doi.org/10.5703/jpur.04.1.06

\section{Keywords}

senescence, aging, transition analysis, Tombos, New Kingdom, Nubia, osteoarthritis, osteoporosis, bioarchaeology, paleopathology 


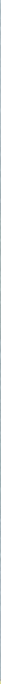

Katelyn Reavis, Anthropology

\section{INTRODUCTION}

Aging is an inescapable truth for humans, no matter how many supplements, juice fads, or treatments we pursue. The oldest cohort is the fastest growing demographic worldwide and presents new challenges for researchers, health care providers, and governments. Exactly how someone reaches extreme old age, which is defined as 80 and above, is still unclear. Research is currently devoted toward successful disease prevention and survival. Understanding senescence in the past through the study of skeletal remains can provide valuable insight about aging today.

Senescence is the cumulative process of becoming old and the physiological changes that accompany that process (Crews, 2003). Senescence also refers to the decline in functioning of an organism due to the progression of its chronological age (Monaco \& Silveira, 2009). In short, it describes the cumulative loss of function and ability as aging progresses. This is a process that is poorly understood in past populations, and if explored further, it would give more meaning to the research that is being done on modern societies.

The recent focus of many modern studies is to examine the oldest of the old, because by studying those who reach extreme old age, we can understand more about successful prevention and disease survival. The more that is known about senescence in the past, the more meaningful our modern research can become, because we will be able to establish a baseline for normative aging patterns in osteoporosis, osteoarthritis, and chronic illness. Generally, those who reach extreme old age, like centenarians, are categorized as disease escapers or disease survivors (Perls \& Silver, 1999). Medical advances have contributed to the number of disease survivors, but there may have been individuals who successfully survived disease in the past as well.

Studies suggest that many of those who reach extreme old age do so because of lifestyle, environment, and genetics (Perls \& Silver, 1999). Lifestyle and environment in modern populations have generally been attributed to medical and technological developments post-Industrial Revolution. The emphasis on genetics is also strong, and many centenarians studied today have confirmed relatives and ancestors who have lived to 100 or late 90 s as well (Perls \& Silver, 1999). These previous generations would have reached extreme old age before the medical advances that are often attributed to extending life today. This suggests that some people were reaching older ages in the past, but due to the general dismissal of their age group in archaeological research, this information remains unknown.

This study examines a sample of older adult remains from the site of Tombos in order to know more about the oldest cohort in ancient Nubia and to better understand senescence in the past. This population was chosen for analysis because it represents an upper- and middle-class society from two different time periods and two cultures, which heavily influenced one another. This research is exploratory in nature and seeks to determine whether or not there were disease survivors, not just disease escapers, within the oldest cohort through time and political transitions at Tombos.

\section{TOMBOS}

Tombos is situated on the third cataract of the Nile in ancient Nubia (modern Sudan), which was a strategic setting for the control of trade and movement along the Nile (Buzon, 


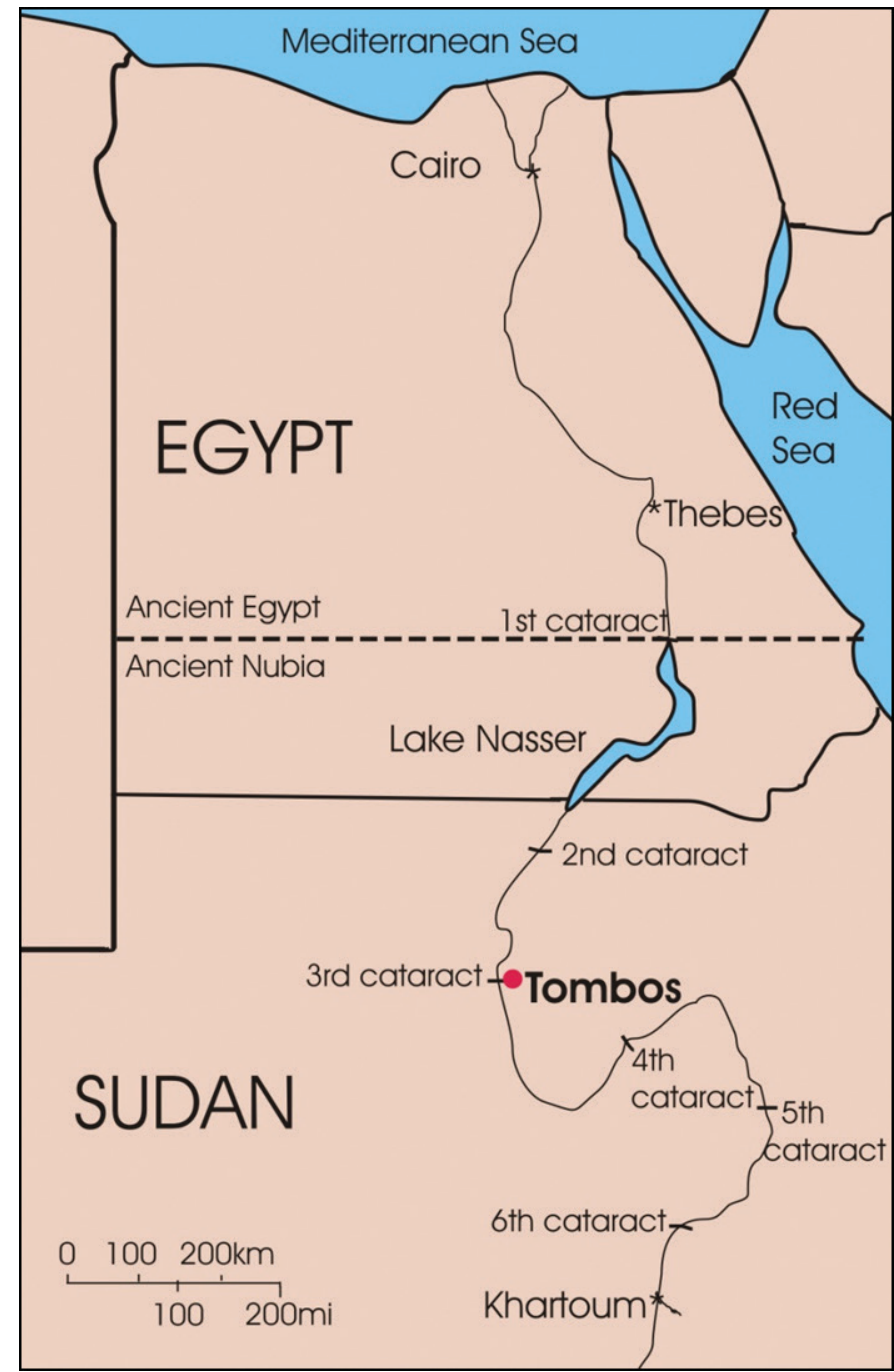

Figure 1. Site of Tombos. Courtesy of Michele R. Buzon.

2006a). Throughout its history, ancient Egypt mounted attacks on its southern neighbor because Nubia possessed rich resources and controlled the main route of trade for these goods (Buzon \& Bombak, 2009). This long history of contact between Egypt and Nubia manifested in diplomatic peace as well as periodic invasions (Buzon, 2006a).

Tombos endured through the transitional period from the Egyptian New Kingdom to the Nubian Napatan state during the Third Intermediate Period, which can be seen by the changes in cemetery structure from its previous use during the New Kingdom colonial period (Buzon \& Richman, 2007). Paleopathological evidence implies peace and cooperation between Egyptians and Nubians buried at the site (Buzon, 2006a). The area containing middleclass mud brick structures was abandoned during the Third Intermediate Period, and a new group of Nubian-style tumuli (burial mounds) was added (Buzon, 2006a). Osteological and archaeological evidence from Tombos indicates that Egyptians and Nubians coexisted and culturally influenced one another throughout both time periods.
A mix of burial practices is present at the site, including the use of coffins, which denote Egyptian style, and funerary beds, which indicate Nubian culture (Schrader, 2012). Osteological examination of metric traits and other archaeological finds determined that the inhabitants of Tombos were biologically heterogeneous (Buzon, 2006a). Overall, the inhabitants of Tombos enjoyed lives that endured little physical stress and were not exposed to harsh physical labor (Schrader, 2012). However, there were some signs of ill health that were associated with environmental stressors (Buzon, 2006b). Tombos was likely a colonial administrative center of the Egyptian empire where inhabitants were upper and middle class, without an aristocracy or peasantry socioeconomic group (Schrader, 2012).

\section{DEMOGRAPHY}

Determining age, especially extreme old age, in past populations has many challenges. When looking at archaeological populations, old age would be categorized as 45 years of age and above. One of the difficulties in understanding senescence in the past revolves around the problem of aging the skeleton after 45 years of age. The issues include methodology, preservation, and bias. Aging the older adult skeleton is done by quantifying processes of degeneration. Instead of clear markers like tooth eruption or epiphyseal fusion, which are used to age juveniles, bioarchaeologists must rely on patterned degenerative changes in the pubic symphysis, auricular surface, and cranial suture closures.

Another issue that surrounds aging the adult skeleton involves the lack of population-specific aging techniques. Many methods were developed using skeletal collections of European, African American, and Native American descent (Milner \& Boldsen, 2012). When these techniques are applied to populations outside of the aforementioned demographics, ages may be biased due to genetic variation and cultural practices. Often age estimates are underestimated when this error occurs (Milner \& Boldsen, 2012). Population-specific aging techniques are still needed and will be a viable resource for researchers in the future (Milner \& Boldsen, 2012).

Overall bone preservation in older adult skeletons is another difficulty that many researchers face. Bone loss and osteoporosis are common among older individuals, which make them more susceptible to the elements and other taphonomic processes, which refer to the process of decomposition of an organism. When this occurs, many traits cannot be scored, or the skeleton is fragmented to the point that the traits are unrecognizable. If a feature is obscured due to preservation, this can lead to underestimation of age. Other tendencies to underestimate the ages of people about 45 years and beyond relate back to the lack of population-specific aging methods. 
Transition analysis is an alternative aging technique that accounts for preservation challenges and bias by scoring the pubic symphysis, auricular surface, and ecto-cranial sutures together to estimate age for the adult skeleton. Transition analysis was used to determine more specific age ranges for each individual, as they were initially categorized only as 45 and above. The presence of each trait is not necessary. This was useful in determining age due to postmortem factors; thus, some features were not present. When every trait is present, it is possible to score 33 features of the skeleton, which are incorporated from the pubic symphysis, auricular surface, and ecto-cranial sutures (Boldsen, Milner, Konigsberg, \& Wood, 2002). This method incorporates different traits on the pelvis (pubic symphysis and auricular surface) and cranium (ecto-cranial sutures), which can give more accurate age estimates than only using a feature on the pelvis alone (Boldsen et al., 2002). Each trait is scored by the researcher and then statistically analyzed as a whole to give a range for age-at-death.

Transition analysis was developed for evaluating ages of all individuals, but this has proven most useful in the older cohort. The age range that is calculated depends on what traits are available and what geographic group is used to analyze scores, which are denoted by "black," "white," and "unknown" categories. The black and unknown categories were used to calculate age, with the black analysis generally giving an older age estimate. The two categories were chosen because transition analysis was developed on African Americans and Europeans, and it was acknowledged that there were likely differences between the ancient Nubian population and modern African Americans.

\section{RESULTS}

\section{Age and Sex Determination}

The sample consisted of 23 individuals, all of whom were able to be sexed. Sex was determined by using standard methods for scoring features on the os coxae (pelvis) and crania (Buikstra \& Ubelaker, 1994). On the os coxae, the ventral arc, subpubic concavity, ischiopubic ramus ridge, greater sciatic notch, and preauricular sulcus were scored. The nuchal crest, mastoid process, supraorbital margin, mental eminence, and prominence of the glabella were examined on the crania. The os coxae and crania traits were scored on a scale of 1 to 5 , and 1 to 3 , respectively.

Of the sample, $34.78 \%(\mathrm{n}=8)$ of individuals are from the New Kingdom $(1400 \mathrm{BC})$, and $65.22 \%(\mathrm{n}=15)$ are from the Napatan Period (750 BC). The New Kingdom sample $(n=8)$ was comprised of $37.5 \%(n=3)$ males and $62.5 \%(\mathrm{n}=5)$ females. The Napatan Period sample $(\mathrm{n}=15)$ was made of $46.67 \%(\mathrm{n}=7)$ males and $53.33 \%$ $(\mathrm{n}=8)$ females. The lowest calculated age was 47 years, and the highest calculated age was 85.8 years. The calculated ages of Napatan Period females ranged from 64.2 to 81.5 years old, whereas males ranged from 47 to 84.2 years old. New Kingdom female age ranges were from 48.5 to 79.3 years old, and males ranged from 68 to 85.8 years old. This population had some of the oldest males in the sample, and the highest ages overall.

In total there were three individuals in their $80 \mathrm{~s}$, nine in their 70s, three in their $60 \mathrm{~s}$, three in their $50 \mathrm{~s}$, and five in their 40s. Five individuals were on the border between decades and were in different calculated age ranges, depending on whether their age was calculated with the "black" or "unknown" analysis categories. Three individuals were between the 70 and 80 category, one individual was between the 60 and 70 , and one was between the 40 and 50 . Overall, men had higher ages than females; however, females were clustered from the $60 \mathrm{~s}$ to $70 \mathrm{~s}$, whereas the males had a greater dispersion of ages.

\section{PALEOPATHOLOGICAL CONDITIONS PRESENT}

Paleopathological analysis is the determination of disease from skeletal remains. Each individual was examined for any traumatic injury, osteoarthritis, porotic hyperostosis, cribra orbitalia, enamel hypoplasia, carious lesions, and abscesses. The presence of these conditions would shed light on any disability and disease experienced. Cribra orbitalia, porotic hyperostosis, and enamel hypoplasia are indicators of nonspecific environmental stress, like nutritional deficiencies (Buikstra \& Ubelaker, 1994).

Concentrated lesions on the eye orbit vaults or parietals indicate porotic hyperostosis and cribra orbitalia (White \& Folkens, 2005). Enamel hypoplasia was determined if an individual exhibited transverse lines, pits, or grooves on the surface of their tooth crowns (White $\&$ Folkens, 2005). These would indicate a period of disrupted tooth growth during childhood, which is often linked to an episode of malnutrition. Carious lesions are characterized as decalcification of enamel or dentine on a tooth (White \& Folkens, 2005). These can cause serious health problems and even lead to death if left untreated due to bacteria entering the bloodstream (White \& Folkens, 2005). Tooth wear was also measured when possible and scored on a scale of 1 to 10, with 10 being the most severe (Buikstra \& Ubelaker, 1994). Extreme tooth wear can lead to carious lesions and other infections in the mouth, so they are important to note as well. Osteoarthritis was determined if the synovial joint face had changed due to bony lipping or osteophytes, and if there was macroporosity or eburnation, or both (Buikstra \& Ubelaker, 1994). 
Osteoarthritis was important to study because it directly affects mobility and is a degenerative process often associated with aging.

Overall, the older population showed few patterns of stress; however, some unique conditions were present. Two healed traumatic injuries were present in two individuals. The first case was a male who had complete spondylolisthesis on a lumbar vertebra. Spondylolisthesis is a fracture that occurs when there is anterior slippage of a vertebral body above it (Mays, 2006). The above vertebral body is affected by a condition called spondylolysis, which usually occurs from repetitive loading of the neural arch (Mays, 2006). Although the cause is not always able to be determined (i.e., we cannot say that a person was definitively laboring in a quarry

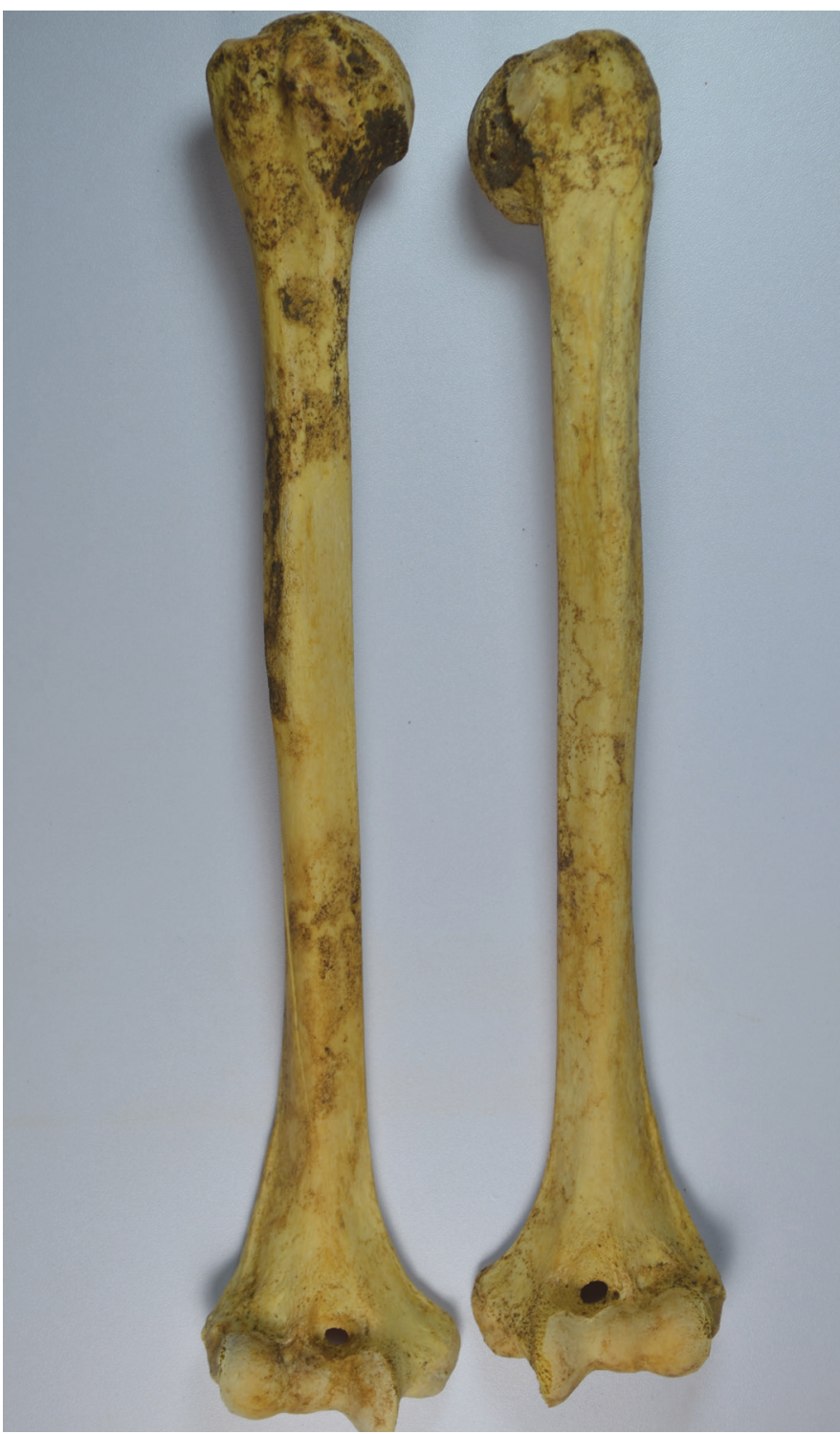

Figure 2. The right humerus has a healed fracture on the proximal aspect (the side nearest to the head or point of attachment). or participating in intensive agricultural practices), the effects of the condition are still felt by the individual. The fracture of a lower thoracic or lumbar vertebra can cause back pain and may limit mobility, impacting the person's daily functioning.

The second instance was a woman whose right humerus was dislocated, and her right fourth, fifth, and sixth ribs had healed fractures as well. The rib fractures were in line with one another and were likely caused from the same incident. The humerus was rotated and healed posteriorly, and it had atrophied. Also, she had a large area of reactive bone on the greater and lesser trochanters of the right femur, which may have been injured during the same episode that affected the humerus and ribs. This woman lived to be in her 70s and could have experienced this injury from a fall. Falls are common in older adults and can often cause other complications that lead to death. This woman survived her episode without modern medicine and continued to thrive. The general absence of trauma is indicative of a middle-class society that was not engaged in hard labor or military service.

Osteoarthritis was present in all individuals, but there was a wide range in severity. The vertebrae were the most significantly affected, especially the lumbar and cervical vertebrae. It was also found on the patella, tarsals, carpals, and hand phalanges. These findings are consistent with previous studies done on the Tombos population as a whole (Schrader, 2012). Two individuals had Schmorl's nodes on their lumbar vertebrae. Schmorl's nodes are depressions from protrusions into the vertebral body and are often found in lumbar vertebrae (Buikstra \& Ubelaker, 1994). These cause pain and discomfort in the affected individuals, which could reduce mobility.

Thirteen individuals were able to be analyzed for porotic hyperostosis and cribra orbitalia; however, ten individuals did not have crania that could be examined. Three individuals displayed porotic hyperostosis. The individual who experienced these nutritional and environmental stresses would have done so for weeks or possibly much longer, which points to the resiliency of the people at Tombos, and possibly people in the past in general.

Determining pathology from dentition was difficult in this population because many teeth were lost antemortem. Reabsorption of bone into the mandible or maxilla was common. This was likely due to carious lesions or serious wear; however, there is no way to determine this definitely. Enamel hypoplasia was not present in the sample, which was unusual and likely due to the amount of teeth lost antemortem. Three carious lesions were found in three different individuals. Two abscesses were found on the left side of the mandible 
of one individual. This is considered abnormally low and likely due to the loss of teeth prior to death. One individual had lost all of his mandibular teeth antemortem, but all of his maxillary teeth were present and in good condition.

Tooth wear was significant at Tombos, which was likely due to a diet high in carbohydrates and sand getting mixed in with their food. One woman had her molars worn down to the dentin at a 45-degree angle. Almost all teeth exhibited significant wear, especially molars, which had worn past the enamel and exposed the dentin beneath.

\section{CASE STUDIES}

A woman with a calculated age of 77.8 years old had complete spina bifida. All of her sacral neural arches, which normally fuse together around 3 to 4 years old, were completely separated. The sacrum was atrophied, which affected the posterior aspect of the ilium, auricular surface, and sciatic notch. This could have impaired her ability to have children, and therefore, could have helped her reach extreme old age. Historically, childbirth has been dangerous for women and would have contributed greatly to death rates in the past.

There also was a large osteophyte growth on the superior aspect of the fourth lumbar that covered the third lumbar in a similar manner, but they were not fused. The third, fourth, and fifth lumbar vertebrae seem to have taken over the support role because the sacrum was atrophied. The legs were not atrophied, which suggests that this condition did not significantly affect her mobility. This can be attributed to the fusion of the lumbar vertebrae, but it is not conclusive. It does point toward a caring social network for those who were disabled.

Another Napatan female presented a different condition that was unique to the sample. Her age at death was calculated to be 74 years old, but could have ranged from 54 to 88 years old. The proximal aspect of her right femur was affected by a large unknown disease or infection. The neck was completely reabsorbed into the shaft, and the head had reabsorbed into itself with healed macroporosity and lipping. Both trochanters were covered in reactive bone, and the lesser trochanter had been completely reabsorbed into the shaft as well. The interior was visible, and it was noted that the cortical bone had deteriorated, which may have been due to osteoporosis. The nature of infection or pathology was extensive enough that it can be assumed that this process of bone reabsorption took months or even longer. The long-term nature of the pathology or possible infection from trauma shows that she survived the initial episode and lived with this condition for some time.

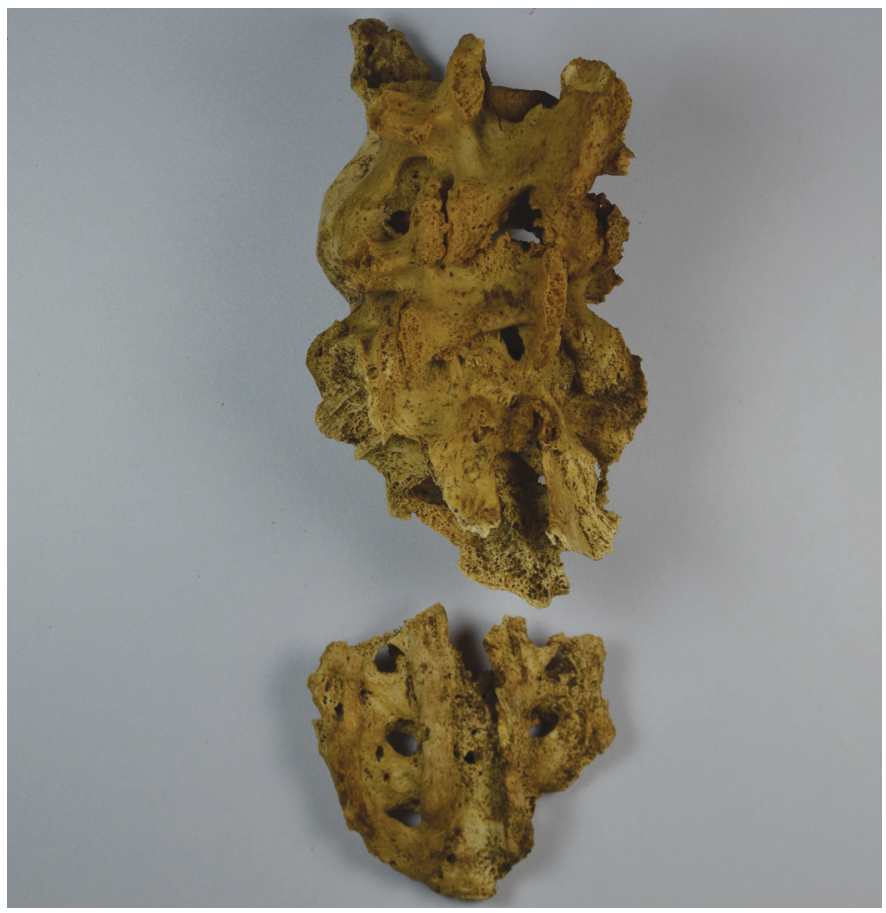

Figure 3. Spina bifida, posterior aspect.

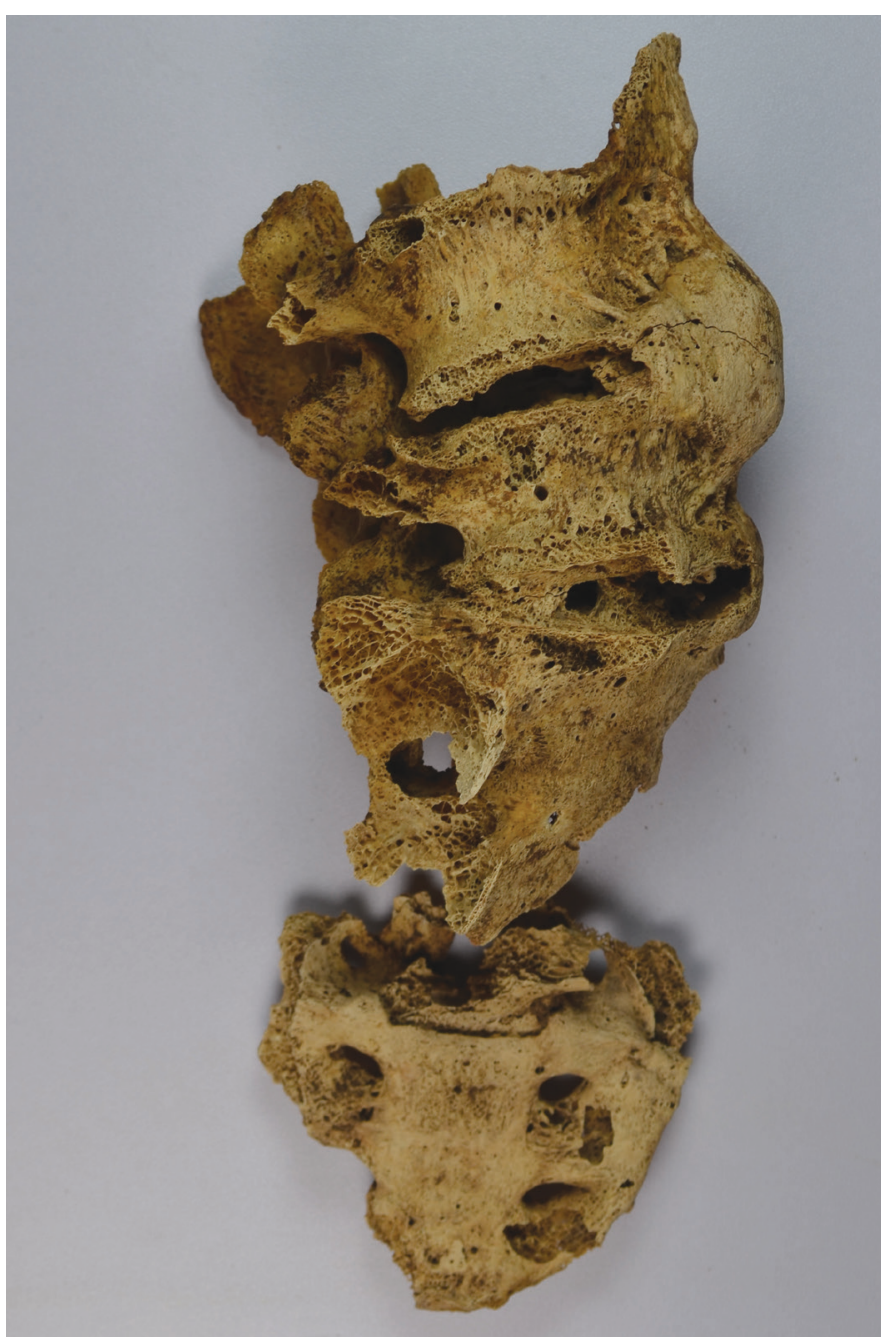

Figure 4. Spina bifida, anterior aspect. 


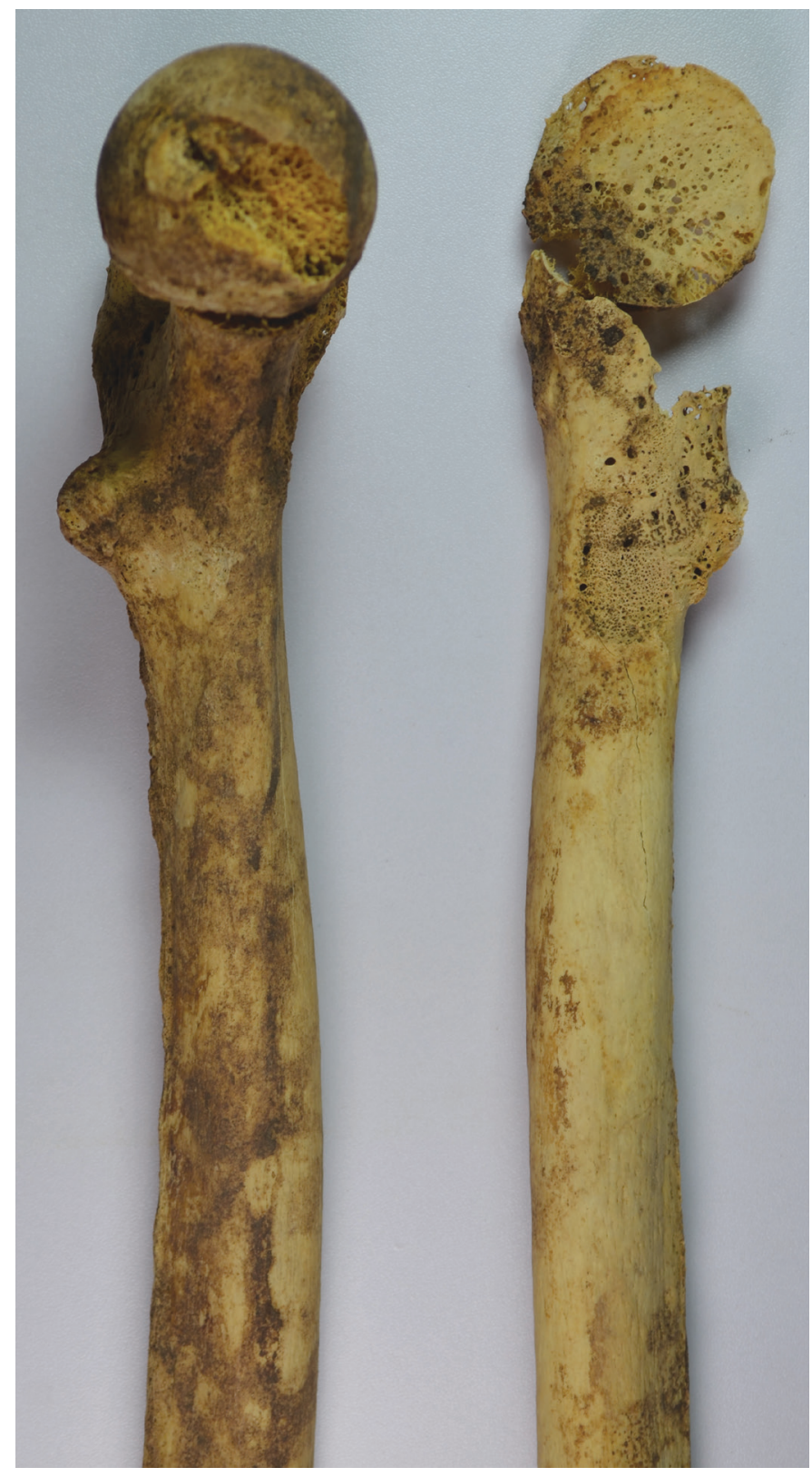

Figure 5. Reabsorbed bone on the proximal aspect of the femur, medial aspect.

Both women were two of the oldest people within this cohort and would be characterized as disease survivors because these illnesses did not seem to keep them from reaching extreme old age for the time period. This is an indication that those who lived to extreme old age in the past did not necessarily do it because they managed to avoid disease throughout their entire life.

\section{FURTHER RESEARCH AND LIMITATIONS}

More research on osteoporosis in the population would be valuable in understanding senescence and the oldest cohort in ancient Nubia. Osteoporosis has become a growing modern health concern, and determining baseline prevalence would be useful. Further research could also examine older demographics during times of transition and conflict in contrast to times of peace and stability. A limitation of this study is the small sample size. This is in part due to the preliminary nature of this work as well as the exclusion of comingled remains. This was necessary because the goal was to create a life history for each individual, and comingled remains would not be able to provide that information.

\section{CONCLUSIONS}

Results from Tombos resembled some of the aging patterns that we see in modern-day centenarians. Today there is a wide variety of people who reach extreme old age, some who have avoided disease their entire life and others who have overcome illness (Perls \& Silver, 1999). At Tombos, there is a variety of disease survivors and disease escapers within the oldest cohort, instead of a homogeneous collection of disease escapers that may initially have been expected.

The case studies show that those who survived disease and traumatic instances can still reach old age. Without modern advances in medicine, it would be easy to assume that those who reached extreme old age were anomalies who avoided disease throughout their lives, but there were many who were able to survive disease and live to old age in ancient Nubia. This could be indicative of cultural, genetic, or environmental factors, or, more likely, due to a combination of those factors.

It is possible that the individuals at Tombos were more genetically predisposed to survive disease than others, and certainly some individuals seemed to avoid chronic disease for their entire life. Some individuals reached advanced ages, and these people were not anomalies. This also could give insight into the importance of older adults in ancient Nubia, and the importance of support structures available to people during that time period. A better understanding of this cohort in other archaeological populations is necessary to understand the broader cultural context of aging as well. Past populations can add valuable information to our understanding of senescence, and therefore, they can help people successfully navigate the changes that accompany aging.

\section{ACKNOWLEDGMENTS}

This research was supported by the Purdue University College of Liberal Arts Margo Katherine Wilke Internship Program. 


\section{REFERENCES}

Boldsen, J. L., Milner, G. R., Konigsberg, L. W., \& Wood, J. W. (2002). Transition analysis: A new method for estimating age from skeletons. In R. D. Hoppa \&

J. W. Vaupel (Eds.), Paleodemography: Age distributions from skeletal samples (73-106). Cambridge: Cambridge University Press. http://dx.doi.org/10.1017 CBO9780511542428.005

Buikstra, J., \& Ubelaker, D. (Eds.). (1994). Standards for data collection from human skeletal remains. Fayetteville: Arkansas Archeological Survey Research Series.

Buzon, M. R. (2006a). Biological and ethnic identity in New Kingdom Nubia. Current Anthropology, 47(4), 683-695. http://dx.doi.org/10.1086/506288

Buzon, M. R. (2006b). Health of the non-elites at Tombos: Nutritional and disease stress in New Kingdom Nubia. American Journal of Physical Anthropology, 130(1), 26-37. http://dx.doi.org/10.1002/ajpa.20303

Buzon, M. R., \& Bombak A. (2009). Dental disease in the Nile Valley during the New Kingdom. International Journal of Osteoarchaeology, 20(4), 1-17. http:// dx.doi.org/10.1002/oa.1054

Buzon, M. R., \& Richman, R. (2007). Traumatic injuries and imperialism: The effects of Egyptian colonial strategies at Tombos in upper Nubia. American Journal of Physical Anthropology, 133(2), 783-791. http://dx.doi.org/10.1002/ajpa.20585
Crews, D. E. (2003). Human senescence: Evolutionary and biocultural perspectives. Cambridge: Cambridge University Press.

Mays, S. (2006). Spondylolysis, spondylolisthesis, and lumbo-sacral morphology in a medieval English skeletal population. American Journal of Physical Anthropology, 131(3), 352-362. http://dx.doi.org/10.1002/ajpa.20447

Milner, G. R., \& Boldsen, J. L. (2012). Estimating age and sex from the skeleton, a paleopathological perspective. In A. L. Grauer (Ed.), A companion to paleopathology (268-284). Oxford: Wiley-Blackwell. http://dx.doi.org/10.1002 /9781444345940.ch15

Monaco, T. O., \& Silveira, P. S. P. (2009). Aging is not senescence: A short computer demonstration and implications for medical practice. Clinics, 64(5), 451-457. http://dx.doi.org/10.1590/S1807-59322009000500013

Perls, T. T., \& Silver, M. H. (1999). Living to 100: Lessons in living to your maximum potential at any age. New York: Basic Books.

Schrader, S. A. (2012). Activity patterns in New Kingdom Nubia: An examination of entheseal remodeling and osteoarthritis at Tombos. American Journal of Physical Anthropology, 149(1), 60-70. http://dx.doi.org/10.1002/ajpa.22094

White, T. D., \& Folkens, P. A. (2005). The human bone manual. Burlington: Academic Press. 